\title{
Synthesis and Characterization of New Thio-Triazole Ligand and Complexes with Selected Metals
}

\author{
${ }^{1}$ Ahmed Majeed and ${ }^{2}$ Khalid W.Y.Zain Alabdeen \\ ${ }^{1,2}$ Department of Chemistry, College of Science, Al-Nahrain University, Baghdad-Iraq.
}

\begin{abstract}
The new ligand, thiocarboxyphenyl-4-allyl-5-phenyl-4H-1,2,4-triazole $(L)$ was prepared and characterized by micro elemental analysis (CHN) and Infrared spectroscopy. Selected metals, which were $\mathrm{Fe}(I I I), \mathrm{Cu}(I I), \mathrm{Cd}(\mathrm{II}), \mathrm{Hg}(\mathrm{II})$ and $\mathrm{Au}(\mathrm{III})$ where reacted with $(L)$ to produce new complexes. These complexes were identified through micro elemental analysis, Infrared and ultraviolet-visible spectroscopy and other techniques. Depending on the data obtained, chemical formula and geometry of complexes were suggested. Biological activity of the complexes against selected types of microorganisms was also examined.
\end{abstract}

Keywords: 1,2,4-triazole, thioamide ligands, chelating ligands, metal complexes.

\section{Introduction:}

1,2,4-Triazole derivatives have consistently attracted scientific and practical interest because of their widely varying chemical properties, synthetic versatility, and pharmacological activities, such as antibacterial, antifungal, anti-tubercular, analgesic, anti-inflammatory, anticancer [1-2]Metal complexes are suggested as a possible measure of drugs, since the action of many drugs is based on the ability of complex compound of metal ions to traverse bio membranes, whereas individual aquo-ions and ligands almost or completely lack this ability. Metal chelates differ in their mode of action and activity in biological systems in accord with their structural considerations, e.g. inert, highly stable metal chelate have a considerable activity against microorganisms, fungi and viruses and are used in controlling the speed of neoplastic tissue[3]. An important and versatile class of well established biologically active compounds are those with the -N-C=S moiety (" soft" sulfur atom besides the " hard" nitrogen). This group is found in many basic structures of drugs either to be part of an open chain ,e.g. thiocarbamates, isothiocynates and thiosemicarbazides or involved in heterocyclic ring,e.g. mercapto derivatives of triazoles, oxadizoles and thiodiazoles [4-6].

In the search for new chemical reagents with strong affinity for certain metal ions, many researchers have indicated that chelating reagents have the advantage of offering better selectivity and specificity as flotation collectors. Therefore, the use of chelating reagents in the flotation process has been paid much attention for many years [7]. Le Borgene et al. reported letrozole analogues having an arylindole moiety with imidazole or 1,2,4-triazole heterocycles, structure activity relationships identified the importance of electron withdrawing groups at the para position of the phenyl with nitrile group being best [8]. The use of triazole complexes of silver for applications in the photographic industry, Another property of triazoles as ligands is that the ligand strength is just in the region to give spin crossover compounds with iron(II) salts. Depending on the substituents the transition temperatures range from about 100 to $400 \mathrm{~K}$. This property means that triazole complexes of iron(II) are studied in the search for spin crossovers at room temperature .Such systems are applicable for information storage . A review on iron(II) triazole complexes was published in 1996 [9].

In this work, we report the preparation of the new ligand " thiocarboxyphenyl-4-allyl-5-phenyl-4H1,2,4-triazole " (L), and some metal complexes. These compounds were prepared with the intention of finding new potentially biologically active compounds.

\section{Instrumentation}

\section{Experimental:}

Melting points were recorded by using Gallenkamp M.F.B. 600.01F of melting point apparatus . Infrared spectra were recorded using Perkin-Elmer 1130 Infrared spectrophotometer as $\mathrm{KBr}$ disk in the range (4000 - 600) $\mathrm{cm}^{-}$.UV-Visible spectra were measured using Shimadzu UV-Vis 160A Ultra-violet spectrophotometer at room temperature using silica cells of $1.0 \mathrm{~cm}$ length. The metal percent in the prepared complexes were determined using atomic absorption technique by Pye Unicam of Philips Scientific Instrument which employed the hollow cathode lamp of the Pye Unicam Itd. Cambridge. Elemental microanalysis was carried out using CHN elemental analyzer model 5500 Carlo-Erba instruments (Italy). Magnetic susceptibility for the prepared complexes were obtained at room temperature using Farady method, by placing the sample in a small pyrex container suspended from a balance through a fine, Nylon thread to the center of electric magnet. For this purpose, Bruker Magnet B.M.6 has been employed. The diamagnetic correction factor D was calculated using Pascal constants. Electric molar conductivity measurements were carried out at room temperature at the 
concentration $\left(10^{3-} \mathrm{M}\right)$ using digital conduct meter type LF521 (WTW). All chemicals were of high purity are used as the manufacturers supplied them. Pyridine was distilled and dried over $\mathrm{KOH}$ pellets. Allyl isothiocynate was redistilled prior to use. The ligand, was prepared according to the following procedure:

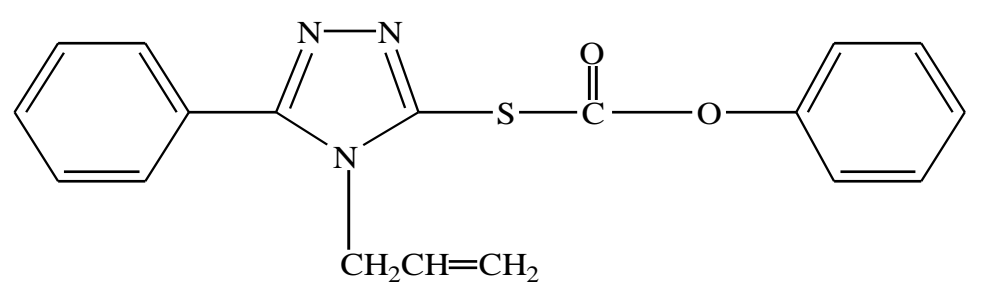

The Ligand (L)

The compound 3-mercapto-4-allyl-5-phenyl-4H-1,2,4-triazole was prepared[10 ] and used as a precursor for the ligand (L). The suspension of 3-mercapto-4-allyl-5-phenyl-4H-1,2,4-triazole $(0.025$ mole, $5.4 \mathrm{~g})$ in pyridine $(50 \mathrm{ml})$ was cooled in ice bath and stirred. To this suspension, chlorophenylformate $(0.025$ mole, $3.9 \mathrm{~g}$ ) was added very slowly and drop wisely. The mixture was then stirred at $50{ }^{\circ} \mathrm{C}$ for $1 \mathrm{hr}$. The resulting faint rosy suspension was kept at room temperature overnight with continuous stirring. It was poured in ice containing water $(\sim 250 \mathrm{ml})$ to give oily product. Dilute $\mathrm{HCl}$ was added until a faint rosy product was formed, filtered and washed several times with water. Recrystallization from ethanol was carried out to produce pale pink $87.50 \%$ yield with a melting point $(106-108){ }^{\circ} \mathrm{C}$.

\section{Metal complexes of $\mathbf{L}$ were prepared as follows:}

(A) $\mathrm{Cu}(\mathrm{II}), \mathrm{Cu}(\mathrm{I}), \mathrm{Cd}(\mathrm{II}), \mathrm{Hg}(\mathrm{II})$, and $\mathrm{Au}(\mathrm{I})$ complexes:

Ethanolic solution of (1 mmole) of the metal salt [ chlorides of $\mathrm{Cu}(\mathrm{II}), \mathrm{Cd}(\mathrm{II}), \mathrm{Hg}$ (II), $\mathrm{Au}(\mathrm{III})$ ] were added to $(2 \mathrm{mmole})$ of $\mathrm{L}$ dissolved in ethanol. The mixture was stirred at room temperature for $1 \mathrm{hr}$. fine precipitate was formed in all cases which was filtered on sintered glass crucible and recrystallized using ethanol : water mixture, then dried under vacuum. Two different complexes were isolated in the case of copper. The first green was isolated immediately after mixing the reagents while the second off- white complex was formed after stirring for a longer time $1 \mathrm{hr}$.

(B) $\mathrm{Fe}(\mathrm{III})$ complex:

The procedure described above was followed to prepare the Fe(III) complex except the reaction mixture was refluxed for $1 \mathrm{hr}$ and the precipitate was then washed several times with ethanol and diethyl ether.

\section{Bacteriology:}

Biological activity of $\mathrm{L}$ and complexes were evaluated against representative gram-positive and gramnegative bacteria by agar plate method[11]. All the compounds were prepared freshly by dissolving them in cultivated in nutrient agar. The results are found in table (4). The solvent DMF was used to obtain a final concentration of $1000 \mathrm{mg} / \mathrm{ml}$. All bacteria were placed on the nutrient agar surface using the loop and by streaking processor.

\section{Discussion:}

The identification of the ligand $\mathrm{L}$ was carried out through elemental analysis : C, $64.31 \%$ (calc.64.09\% ) ; $\mathrm{H}, 4.30 \%(4.45 \%) ; \mathrm{N}, 12.32 \%(12.465 \%)$. The olefinic group in the ligand responded positively to both $\mathrm{Br}_{2} /$ $\mathrm{CCl}_{4}$ and $\mathrm{KMnO}_{4}$ tests. The ligand was found to be soluble in ethanol, acetone, carbon tetrachloride, diethyl ether and DMF. It is found to be insoluble in the n-hexane. Identification of the complexes was done using different available techniques. Among these techniques are the determinations of metal percentage by atomic absorption, infrared, magnetic susceptibility and conductivity measurements.

Table(1) lists some physical data of the prepared complexes.

\begin{tabular}{|c|c|c|c|c|c|}
\hline $\begin{array}{l}\text { Complex of L } \\
\text { with metal ion }\end{array}$ & Color & Yield\% & $\begin{array}{l}\text { Melting point, } \\
\square \mathrm{C}\end{array}$ & M\% calculated & $\begin{array}{l}\text { M\% } \\
\text { found }\end{array}$ \\
\hline $\mathrm{Hg}(\mathrm{II}), \mathrm{C}_{1}$ & White & 80 & $(140-143)$ & 30.65 & 30.54 \\
\hline $\mathrm{Au}(\mathrm{I}), \mathrm{C}_{2}$ & White & 51 & $(131-134)$ & 21.73 & 22.57 \\
\hline $\mathrm{Cd}(\mathrm{II}), \mathrm{C}_{3}$ & White & 86 & $(146-148)$ & 19.85 & 20.23 \\
\hline $\mathrm{Cu}(\mathrm{I}), \mathrm{C}_{5}$ & Off white & 75 & $(168-170)$ & 11.07 & 11.33 \\
\hline $\mathrm{Fe}(\mathrm{III}), \mathrm{C}_{6}$ & Brown & 34 & $(>250) \mathrm{d}$ & 14.57 & 14.80 \\
\hline
\end{tabular}




\section{Identification}

The ligand is characterized by the presence of the ester group that is incorporated in the triazole structure at the sulfur atom in the form of phenyl formate as shown above. The IR spectrum of L exhibited a strong band at $1770 \mathrm{~cm}^{-1}$ and another strong band at $1240 \mathrm{~cm}^{-1}$. These are diagnostic bands or the ester group corresponding to $v(\mathrm{C}=\mathrm{O})$ and $v(\mathrm{C}-\mathrm{O})$ respectively [12]. Table(2) shows the vibration bands exhibited by the ligand and its complexes. It is noticed that in ester metal complex $v(\mathrm{C}=\mathrm{O})$ is shifted to lower frequency, while $v(\mathrm{C}-\mathrm{O})$ is shifted to higher frequency by complex formation. These shifts are depending on the metal ion. The magnitude of the hit follows the well-known Irving-William's order [13].

\section{A-Mercury (II) complex; $\mathrm{C}_{1}$}

The IR spectrum of $\mathrm{C}_{1}$ shows a marked change in the ester group vibrations. The band at $1770 \mathrm{~cm}^{-1}$ disappeared and it was suggested that it underwent a red shift to a region less than $1600 \mathrm{~cm}^{-1}$ which already contains strong bands of other vibration[13]. A new band was observed at 1290 which refers to the blue shift of the $v(\mathrm{C}-\mathrm{O})$ by $50 \mathrm{~cm}^{-}$. These observations indicate the coordination of $\mathrm{Hg}$ (II) with the oxygen of the carbonyl group. A broad band at $3400 \mathrm{~cm}^{-1}$ indicates the presence of ethanol molecule in the structure of the complex. Conductivity measurements show the complex to be non-ionic, Table (3), therefore the following bridging structure can be suggested:

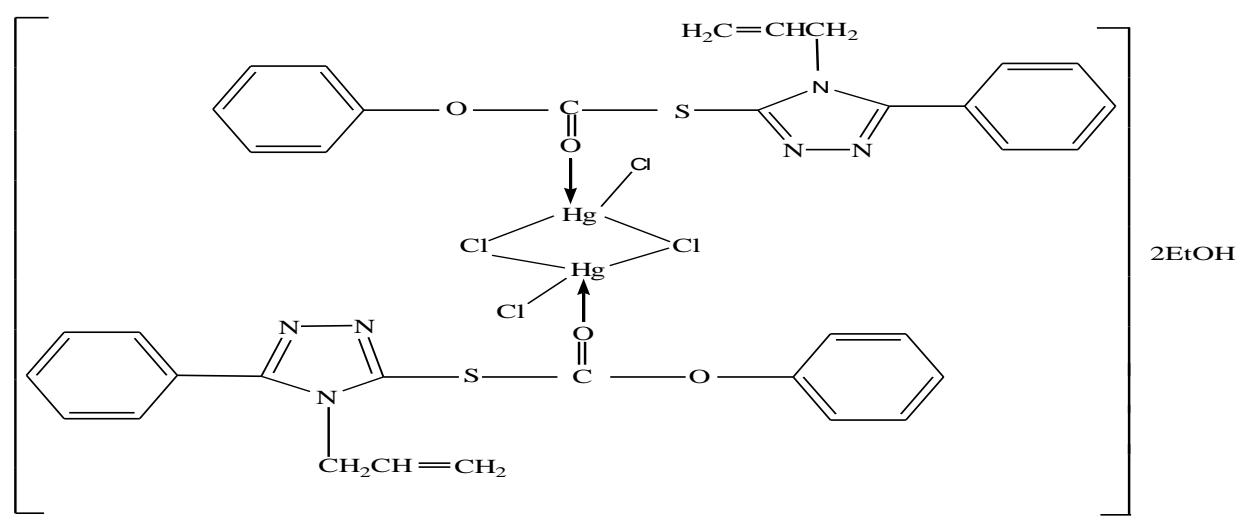

\section{B-Gold (I) complex, $\mathrm{C}_{2 \text { : }}$}

The IR spectrum of $\mathrm{C}_{2}$ shows no change in the ester group vibrations, while a change in the olefinic group has been noticed for both $v(\mathrm{C}=\mathrm{C})$ and out of plane $\delta\left(=\mathrm{CH}_{2}\right)$. The first stretching vibration was shifted to a region lower than $1550 \mathrm{~cm}^{-1}$, while the second bending vibration was observed at $845 \mathrm{~cm}^{-1} .\left(55 \mathrm{~cm}^{-1}\right.$ lower than the free ligand)[13]. A shift was also observed for the $v$ (N...C...S) thioamide band III [14 ] by $10 \mathrm{~cm}^{-1}$. These observations suggest that the bonding of $\mathrm{Au}(\mathrm{I})$ ion with the ligand was through the olefinic group and the sulfur atom. This behavior is expected for the soft $\mathrm{Au}$ (I) ion should seek to bind to the soft sulfur atom rather than the hard oxygen atom [13]. As a result of these observations the following structure can be supposed:

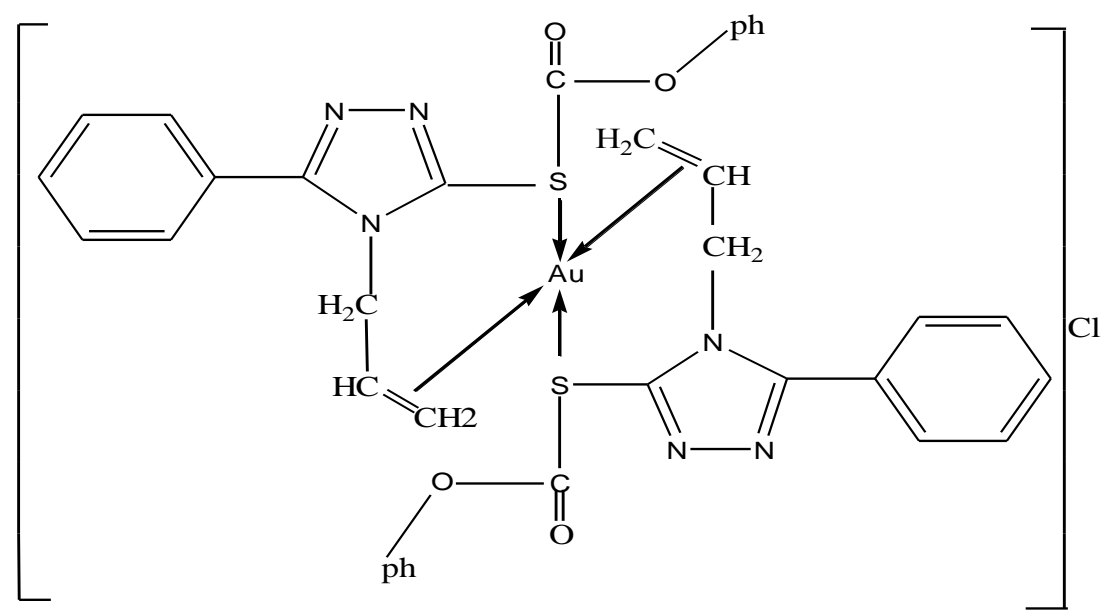

This type of coordination has been documented in the literature[15 ]. Conductivity measurements shows that the above complex is ionic, Table (3). 


\section{C-Cadmium (II) complex; $\mathrm{C}_{3}$ :}

The IR spectrum of $\mathrm{C}_{3}$ complex shows the shifting of the $v(C=O)$ band to a region lower than $1650 \mathrm{~cm}^{-1}$ . The band that corresponds to $v(\mathrm{C}-\mathrm{O})$ was shifted to a lower frequency by $20 \mathrm{~cm}^{-1}$, moreover the band at 1550 $\mathrm{cm}^{-1}$ which corresponds to $v(\mathrm{C}=\mathrm{N})$ was shifted to a lower frequency by $10 \mathrm{~cm}^{-1}$. These observations indicate the participation of both oxygen of carbonyl group and the nitrogen of the thioamide group in the coordination to the metal. A broad band appeared at $3450 \mathrm{~cm}^{-1}$ indicating the presence of ethanol molecule in the structure. Conductivity measurements showed that the complex is non-ionic and the structure of this complex can be depicted as follows:

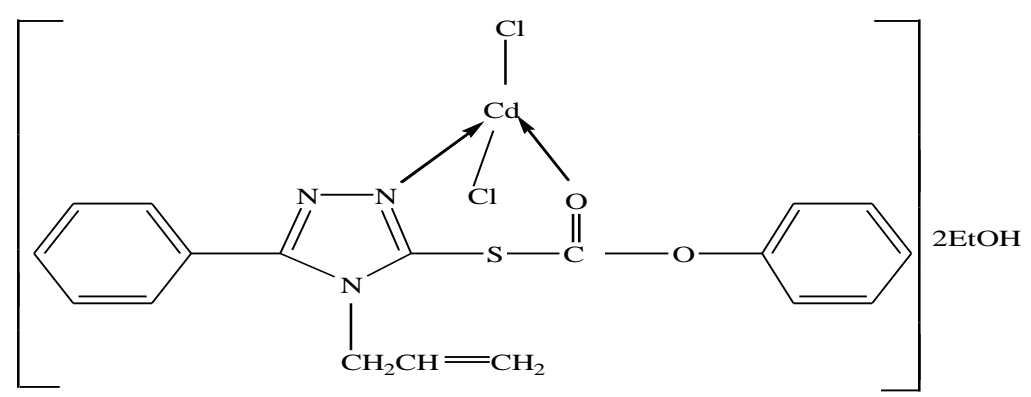

\section{D-Copper (II) complex; $\mathrm{C}_{4}$ :}

The IR spectrum of $\mathrm{C}_{4}$ complex showed the shifting of the $\mathrm{v}(\mathrm{C}=\mathrm{O})$ band to a lower frequency at region below $1650 \mathrm{~cm}^{-1}$. A new band was observed at $1290 \mathrm{~cm}^{-1}$ that may refer to the shifting of $\mathrm{v}(\mathrm{C}-\mathrm{O})$ to a higher frequency. The $v(C=N)$ was also shifted to a lower frequency by $10 \mathrm{~cm}^{-1}$. Metal analysis pointed out to the presence of two copper atoms per each molecule of the complex. Infrared data indicate that the first $\mathrm{Cu}$ (II) ion coordinates to the ligand through the oxygen of the carbonyl group and the nitrogen of the thioamide group. The other copper ion coordinates to the oxygen of the ester group only. A broad band appeared at $3500 \mathrm{~cm}^{-1}$ indicates the presence of water molecule in the structure.

The structure of complex may be suggested:

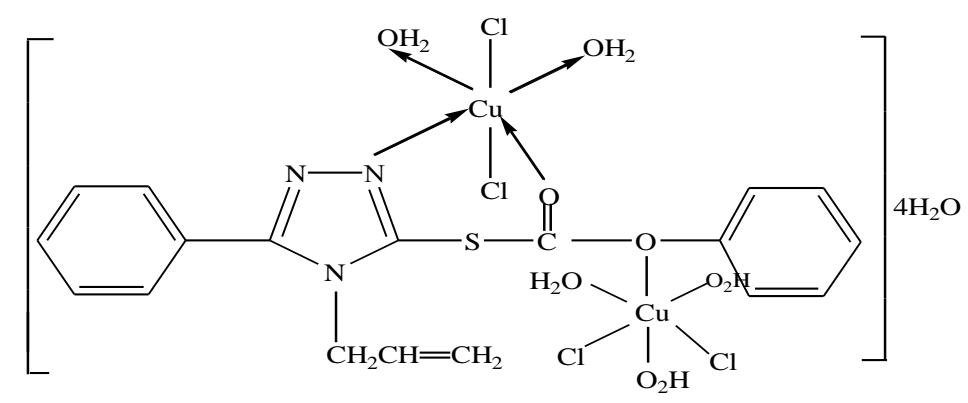

\section{E-Copper (I) complex; $\mathrm{C}_{5}$ :}

The IR spectrum of $\mathrm{C}_{5}$ complex shows the following changes compared to the free ligand : the $v(C=O)$ band was shifted to a region below $1650 \mathrm{~cm}^{-1}$. The band that corresponds to $v(\mathrm{C}-\mathrm{O})$ was also shifted to a higher frequency by $20 \mathrm{~cm}^{-1}$. The $v(\mathrm{C}=\mathrm{N})$ was shifted to a lower frequency by $10 \mathrm{~cm}^{-1}$. Therefore, $\mathrm{Cu}(\mathrm{I})$ may coordinate with $\mathrm{L}$ through oxygen of the carbonyl group and nitrogen of the thioamide group. A broad band appeared at $3400 \mathrm{~cm}^{-1}$ indicates the presence of ethanol molecule in the structure. The structure of the complex may be suggested as follows:

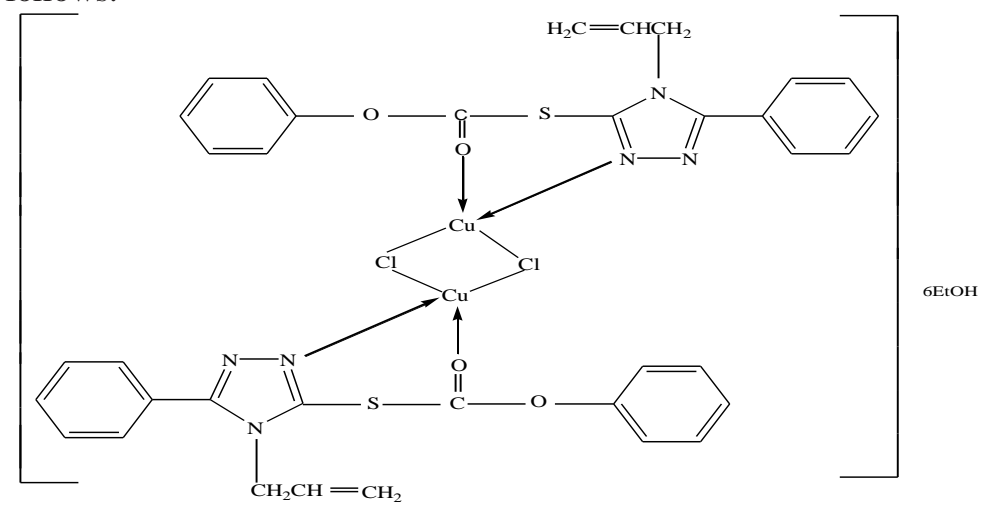




\section{F- Iron (III) complex; $\mathrm{C}_{6}$ :}

The IR spectrum of $\mathrm{C}_{6}$ complex was characterized by a broad in the region (300-3600) $\mathrm{cm}^{-1}$ which could be attributed to the $v(\mathrm{O}-\mathrm{H})$ of water molecule bonded to the Fe(III) ion. This is expected in iron (III) complexes due to its high affinity for water. The ligand can not displace all the water molecules found in the coordination sphere of the metal ion[15]. The broadening of the band was also noticed in the region ( 16001700) $\mathrm{cm}^{-1}$ which is attributed to the vibration of water molecule. This broadening affects the shape of the spectrum and makes the interpretation more difficult. No absorption band was found at $1770 \mathrm{~cm}^{-1}$ and the carbonyl group is then expected to coordinate with the iron (III) ion through oxygen atom. Furthermore, the $v(C=N)$ band was shifted to a lower frequency by $20 \mathrm{~cm}^{-1}$. This may suggest the participation of the nitrogen atom of the thioamide group in addition to the oxygen of the carbonyl group in coordination. According to the metal analysis percentage, one molecule of complex contains two atoms of iron and the following structure is suggested:

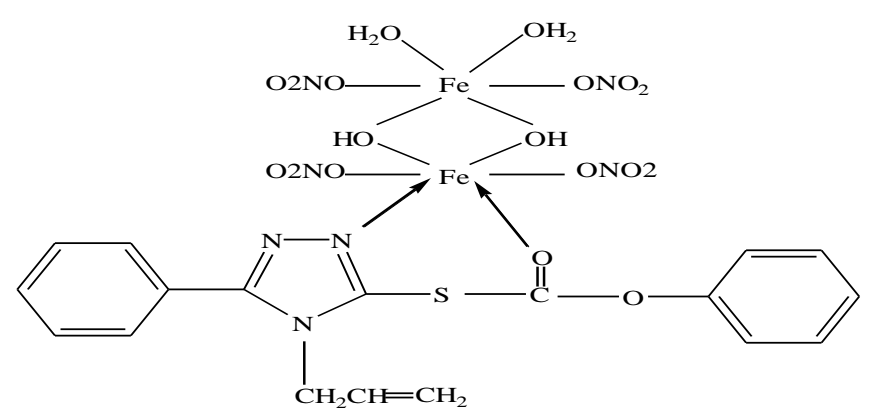

Table (2) Absorption bands of infrared spectra of the $\mathrm{L}$ and its complexes

\begin{tabular}{|c|c|c|c|c|c|c|c|}
\hline Symbol & $v(\mathrm{O}-\mathrm{H})$ & $\begin{array}{c}\text { Thioamide } \\
\text { band(II) } \\
v(\mathrm{C}=\mathrm{N}+\mathrm{C}=\mathrm{S})\end{array}$ & $\begin{array}{c}\text { Thioamid } \\
\text { band(IV) } \\
v(\mathrm{C}-\mathrm{S})\end{array}$ & $v(\mathrm{C}=\mathrm{N})$ & $v(\mathrm{C}=\mathrm{O})$ & $v(\mathrm{C}-\mathrm{O})$ & $\delta(\mathrm{O}-\mathrm{H})$ \\
\hline $\mathrm{L}$ & - & $1270(\mathrm{~m})$ & $770(\mathrm{~m})$ & $1550(\mathrm{~m})$ & $1770(\mathrm{~s})$ & $1240(\mathrm{~m})$ & - \\
\hline $\mathrm{C}_{1}$ & $3400(\mathrm{~b})$ & $1280(\mathrm{w})$ & $770(\mathrm{~m})$ & $1550(\mathrm{~m})$ & - & $1290(\mathrm{w})$ & $920(\mathrm{w})$ \\
\hline $\mathrm{C}_{2}$ & - & $1280(\mathrm{w})$ & $760(\mathrm{~m})$ & $1550(\mathrm{~m})$ & $1760(\mathrm{w})$ & $1240(\mathrm{~m})$ & - \\
\hline $\mathrm{C}_{3}$ & $3450(\mathrm{~b})$ & $1275(\mathrm{~m})$ & $770(\mathrm{~m})$ & $1540(\mathrm{w})$ & 1650 & $1260(\mathrm{~m})$ & $920(\mathrm{w})$ \\
\hline $\mathrm{C}_{4}$ & $3500(\mathrm{~b})$ & $1280(\mathrm{w})$ & $770(\mathrm{~m})$ & $1540(\mathrm{w})$ & 1600 & $1290(\mathrm{w})$ & $915(\mathrm{w})$ \\
\hline $\mathrm{C}_{5}$ & $3400(\mathrm{~b})$ & $1280(\mathrm{w})$ & $770(\mathrm{~m})$ & $1540(\mathrm{w})$ & 1650 & $1260(\mathrm{w})$ & $920(\mathrm{w})$ \\
\hline $\mathrm{C}_{6}$ & $(3000-$ & $1280(\mathrm{w})$ & $770(\mathrm{~m})$ & $1530(\mathrm{w})$ & - & $1260(\mathrm{w})$ & $915(\mathrm{w})$ \\
\hline
\end{tabular}

Where $\mathrm{s}=$ strong, $\mathrm{m}=$ medium, $\mathrm{w}=$ weak, $\mathrm{b}=$ broad

Table (3) shows the magnetic moment and conductivity measurement results for the complexes at room temperature.

Table (3) Magnetic moment, conductivity and suggested structure for complexes

\begin{tabular}{|c|c|c|c|}
\hline Complex & $\begin{array}{c}\text { Magnetic moment } \\
\text { Meff(B.M.) }\end{array}$ & $\begin{array}{c}\text { Conductivity } \\
\text { Ms.cm }\end{array}$ & Suggested structure \\
\hline $\mathrm{C}_{1}$ & Diamagnetic & 29 & Tetrahedral \\
\hline $\mathrm{C}_{2}$ & Diamagnetic & 72 & Tetrahedral \\
\hline $\mathrm{C}_{3}$ & Diamagnetic & 22 & Tetrahedral \\
\hline $\mathrm{C}_{4}$ & 2.00 & 31 & Octahedral \\
\hline $\mathrm{C}_{5}$ & Diamagnetic & 19 & Square planar \\
\hline $\mathrm{C}_{6}$ & 5.15 & 21 & Octahedral \\
\hline
\end{tabular}

\section{Electronic spectral analysis and magnetic measurements}

The electronic spectra of $\mathrm{Hg}(\mathrm{II}), \mathrm{Cd}(\mathrm{II}), \mathrm{Cu}(\mathrm{I})$ and $\mathrm{Au}(\mathrm{I})$ complexes in the visible region are of little help. These ions have the $\mathrm{d}^{10}$ configuration and therefore their complexes should not exhibit any d-d transition. All the complexes of these metal ions were found to be diamagnetic.

$\mathrm{Cu}$ (II) complex, C4:

$\mathrm{Cu}$ (II) compounds are blue or green because of a single broad absorption band in the region (1100016000) $\mathrm{cm}^{-1}$ [16]. The $\mathrm{d}^{9}$ ion is characterized by large distortion from octahedral symmetry and the band is 
unsymmetrical, being the result of a number of transitions, which are by no means easy to assign unambiguously. However, the band could be assigned to the ${ }^{2} \mathrm{~B}_{1 \mathrm{~g}} \rightarrow{ }^{2} \mathrm{~B}_{2 \mathrm{~g}},{ }^{2} \mathrm{~B}_{1 \mathrm{~g}} \rightarrow{ }^{2} \mathrm{E}_{\mathrm{g}}$ transitions.

The magnetic moment of $\mathrm{C}_{4}$ was (2.0 B.M.) which refers to mononuclear $\mathrm{Cu}$ ( II) octahedral complex.[17]

$\mathrm{Fe}$ (III) complex $\mathrm{C}_{6}$ :

The electronic spectrum of $\mathrm{C}_{6}$ shows two bands, the first one at $20,408 \mathrm{~cm}^{-1}$.

${ }^{6} \mathrm{~A}_{1 \mathrm{~g}} \rightarrow{ }^{4} \mathrm{~T}_{\mathrm{g}}\left(20,408 \mathrm{~cm}^{-1}\right)$

${ }^{6} \mathrm{~A}_{1 \mathrm{~g}} \rightarrow{ }^{4} \mathrm{~T}_{2 \mathrm{~g}}(\mathrm{G})\left(26,455 \mathrm{~cm}^{-1}\right)$

The value of the measured magnetic moment for $\mathrm{C}_{6}$ is (5.15 B.M.), which could be related to high spin $\mathrm{d}^{5}$ ferric ion octahedral geometry is suggested to this complex. From Tanabe-sugano diagram for $\mathrm{d}^{5}$ octahedral field, the value of $10 \mathrm{Dq}$ was found to equal to $20,695 \mathrm{~cm}^{-1}$ and the high value of nephelauxetic factor $(\beta)(0.88)$ indicated the ionic character of the complex[18].

\section{Bactericidal activity:}

Preliminary screening experiments are intended to detect the in vitro activity of $\mathrm{L}$ and its metal complexes [19]. The complexation of $\mathrm{L}$ with all the metal ions use exhibited no activity except $\mathrm{Cu}$ (II); $\mathrm{C}_{4}$ and $\mathrm{Cu}(\mathrm{I}) ; \mathrm{C}_{5}$ complexes These two complexes showed noticeable activity against Staph. Aureus. This activity however was lower than the free ligand, as shown in Table(4).

Table (4) Biological activity for ligand and complexes (at concentration of $1 \mathrm{mg} / \mathrm{mL}$ )

\begin{tabular}{|c|c|c|}
\hline Symbols & Staphylococcus aureus & Escherichia Coli \\
\hline $\mathrm{L}$ & +++ & ++ \\
\hline $\mathrm{C}_{3}$ & - & - \\
\hline $\mathrm{C}_{4}$ & ++ & - \\
\hline $\mathrm{C}_{5}$ & ++ & - \\
\hline $\mathrm{C}_{6}$ & - & - \\
\hline
\end{tabular}

\section{References:}

[1] D. Sahin, H. Bayrak, A. Demirbas, N. Demirbas, S. Alpay Karaoglu, " Design and synthesis of new 1,2,4-triazole derivatives containing morpholine moiety as antimicrobial agents",Turk J Chem, Vol.36, 2012, P.411-426.

[2] P. P. Gadhave, N. S. Dighe, S. R. Pattan, P.Deotarse, D.S. Musmade and R. V. Shete," Current biological and synthetic profile of triazoles: A review" ,Vol.1, No.1,2010, P.82-89.

[3] N. K. Singh, M. Singh, P. Tripathi, A. K.Srivastava and R. J. Butcher ," Synthesis of new N,N-ethane-1,2-bis(4-methoxyphenyl) carbothioamide ligand and its $\mathrm{Cu}(\mathrm{I})$ and $\mathrm{Ag}(\mathrm{I})$ complexes", Polyhedron, Vol.27,No.1 , 2008, P.375-382.

[4] S. Guveli and B. Ulkuseven,"Nickel (II)-triphenylphosphine complexes of ONS and ONN chelating 2-hydroxyacetophenone thiosemicarbazones", Polyhedron, Vol.30,No.8 ,2011, P.1385-1388.

[5] C. Alagöz, D. J. Brauer, F.Mohr, "Arene rethenium metallacyclles containing chelating thioamide liands",Journal of Organometallic Chemistry,Vol.694, No.9-10, 2009, P.1283-1288.

[6] N. Jaiswal, A. Singh, D.Singh, T. Ahmed," A comprehensive review on antimicrobial activity of 1,3,4-oxadiazole derivatives",International Research Journal of Pharmacy,Vol. 3,No.3, 2012, P.83-89.

[7] H. Yekeler . M. Yekeler," Predicting the efficiencies of 2-mercaptobenzothiazole collectors used as chelating agents in flotation processes: a density-functional study ",

Model ,Vol. 12, 2006, P. 763-768.

[8] J. Doiron, Al H. Soultan, R. Richard, M. M. Toure, N. Picot, R. Richard, M. Cuperlovic -Culf, G. A. Robichaud and M. Touaibia," Synthesis and structure-activity relationship of 1- and 2-substituted-1,2,3-triazole letrozole-based analogues as aromatase inhibitors", European Journal of Medicinal Chemistry,Vol.46, 2011, No. 4010 - 4024.

[9] J. G. Haasnoot, "Mononuclear, oligonuclear and polynuclearmetal coordination compounds with 1,2,4-triazole derivatives as ligands", Coordination Chemistry Reviews, Vol. 200-202, 2000, P.131-185.

[10] A.R.Ohi,H.Iwano,T.Shishido,I.Shimamura,Ger.Offen. 1, 1970,935.

[11] B.G.A.Washington,"laboratory Procedure in Chemical Microbiology", Springer-Verlag,New York,1981

[12] R. M. Silverstien, F.X. Webster and D. J. Kiemle," Spectrometric identification of organic compounds", John Wiley, New York, $7^{\text {th }}$ Ed., 2005,

[13] K. Nakamoto ," Infrared of inorganic and coordination compounds ", John Wiley, New York, $6^{\text {th }}$ Ed., 1997.

[14] G.Monossakis,Eur.Med.Chem,22,1987,241.

[15] Cotton F.A., Wilkinson G., Murillo C.A. and Bochmann M., "Advanced inorganic chemistry", Wiley Interscience, Canada, $6^{\text {th }}$ Ed., 1999.

[16] Greenwood N.N. and Earnshaw A.,"Chemistry of the elements", $2^{\text {ed }}$ E d., Elsevier Science Ltd.,2002.

[17] C.K. Jorgenson,"Optical Spectra and Chemical Bonding in Inorganic Chemistry",Springer Verlag,New York ,2004.

[18] Majeed A., Yousif E. and Farina Y.,"Synthesis and Characterization of Transition Metal Complexes of 2-Thioacetic Acid Benzothiazole ligand", Vol.13(1),2010,P.36-42.

[19] X. Zhang, H Song, O Li, X Liu and L. Tang, Polyhedron, Vol. 26,2007,3743. 